\title{
A Practical Guide to the Treatment of Neurogenic Orthostatic Hypotension
}

\author{
Michael J. Berger, Kurt Kimpinski
}

\begin{abstract}
Neurogenic orthostatic hypotension $(\mathrm{NOH})$ is a debilitating condition associated with many central and peripheral neurological disorders. It has a complex pathophysiology and variable clinical presentation, which makes diagnosis and treatment difficult. Neurogenic orthostatic hypotension is often confused with other disorders of orthostatic intolerance, hypovolemic states and systemic conditions. Diagnosis is usually made by an autonomic specialist following characteristic responses to head-up tilt. Symptom control can be achieved through a combination of patient education, nonpharmacologic and pharmacologic therapy. The purpose of this review is to provide the clinician with a practical approach to the diagnosis and management of $\mathrm{NOH}$.
\end{abstract}

\begin{abstract}
RÉSUMÉ: Un guide pratique de traitement de l'hypotension orthostatique neurogène. L'hypotension orthostatique neurogène (HON) est une maladie invalidante associée à plusieurs troubles neurologiques centraux et périphériques. La physiopathologie de l'HON est complexe et son mode de présentation clinique est variable, ce qui rend le diagnostic et le traitement difficiles. L'HON est souvent confondue avec d'autres troubles d'intolérance orthostatique, des états hypovolémiques et des maladies systémiques. Le diagnostic est habituellement fait par un spécialiste du système nerveux autonome lors d'un test d'inclinaison. Le contrôle des symptômes peut être obtenu grâce à l'éducation du patient et un traitement tant non pharmacologique que pharmacologique. Le but de cette revue est de fournir au clinicien une approche pratique pour le diagnostic et le traitement de l’HON.
\end{abstract}

Can J Neurol Sci. 2014; 41: 156-163

Neurogenic orthostatic hypotension $(\mathrm{NOH})$ is a debilitating condition associated with reduced quality of life, impairment in function and is also an independent predictor of mortality. ${ }^{1-3}$ Neurogenic orthostatic hypotension has a complex pathophysiology, variable presentation and broad differential diagnosis making it difficult to diagnose and manage. Neurogenic orthostatic hypotension is defined clinically as a sustained fall in systolic blood pressure $(\mathrm{SBP}) \geq 20 \mathrm{mmHg}$ or diastolic blood pressure (DBP) $\geq 10 \mathrm{mmHg}$ within three minutes (min) of standing from a supine or seated position. ${ }^{4}$ Alternatively, defining $\mathrm{NOH}$ as a fall in postural $\mathrm{SBP} \geq 30$ mmHg may improve the false positive rate from $5 \%$ to $1 \% .^{5}$

Neurogenic orthostatic hypotension can be differentiated from other causes of orthostatic hypotension in that a lesion is present in the autonomic nervous system impeding sympathetic outflow, ultimately resulting in inadequate cerebral perfusion pressure. ${ }^{6}$ Diagnosis of $\mathrm{NOH}$ is usually made after referral to a neurologist or cardiologist with subspecialty training in disorders of the autonomic nervous system (i.e. dysautonomias), using a battery of laboratory measures of autonomic function including head-up tilt (HUT). However, these patients will present initially to the general practitioner, internist, general neurologist or cardiologist and these clinicians must be aware of the causes, clinical presentation, assessment and management of $\mathrm{NOH}$ so that patients can receive consistent, multi-disciplinary care. The purpose of this review is to provide these clinicians with a practical approach to $\mathrm{NOH}$, with a particular focus on diagnosis and management. Detailed reviews for those clinicians that routinely deal with autonomic disorders are available elsewhere. ${ }^{6-8}$

\section{Causes of NOH}

Moving from supine or sitting to standing results in a gravitymediated redistribution of $\sim 500-1000 \mathrm{~mL}$ of blood to the lower extremities as well as a reduction in plasma volume..$^{7}$ This causes reduced end-diastolic volume, ultimately leading to reduced stroke volume and cardiac output. Reduced cardiac output is perceived by the aortic and carotid baroreceptors and this signal is relayed centrally. Healthy humans respond through increasing sympathetic outflow to blood vessels and the heart (with a complimentary reduction in vagal tone), causing

From the Division of Physical Medicine and Rehabilitation (MJB), University of British Columbia, Vancouver, British Columbia; Department of Clinical Neurological Sciences (KK), London Health Sciences Centre and Schulich School of Medicine \&

Dentistry, Western University, London, Ontario, Canada.

Received June 26, 2013. Final Revisions Submitted October 3, 2013. Correspondence to: Kurt Kimpinski, London Health Sciences Centre, University Hospital, 339 Windermere Road, London, Ontario, N6A 5A5, Canada.

Email: kurt.kimpinski@lhsc.on.ca. 


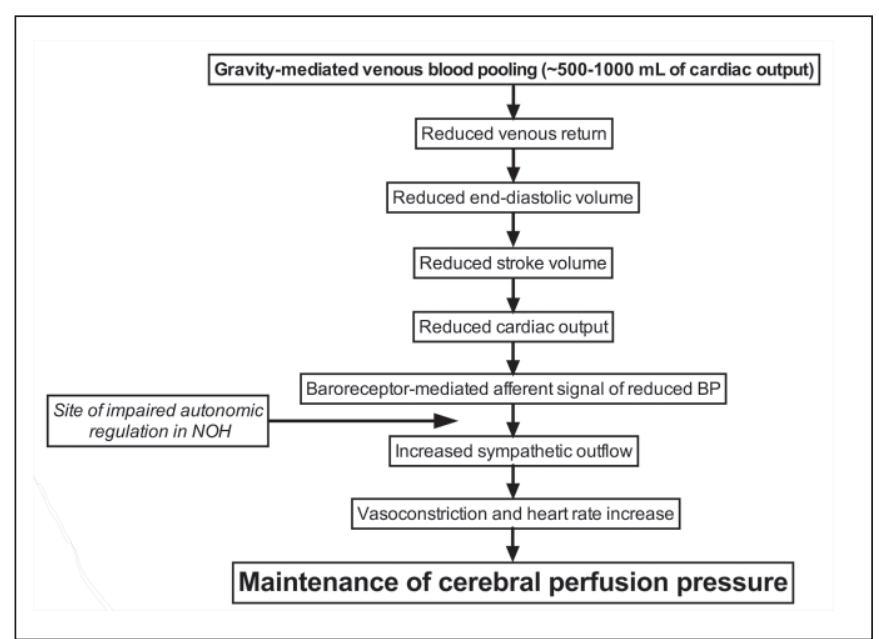

Figure 1: Schematic depicting a simplified approach to understanding the pathophysiology of neurogenic orthostatic hypotension.

vasoconstriction and an elevation in heart rate in order to improve venous return and cardiac output. This mechanism is aided by the effect of the skeletal muscle pump, whereby isometric muscle contractions of the lower extremity musculature also improve venous return. In a simplified model of the pathophysiology of $\mathrm{NOH}$, patients with central and peripheral autonomic lesions have reduced or absent sympathetic responses to orthostatic stress resulting in reduced cerebral perfusion pressures, ultimately leading to $\mathrm{NOH}$ symptoms (Figure 1; for a full review of $\mathrm{NOH}$ pathophysiology, see reference ${ }^{9}$ ).

Neurogenic orthostatic hypotension is not a disease process in itself, but rather a consequence of other diseases. ${ }^{6}$ It is classically associated with a group of neurodegenerative diseases characterized pathologically by the deposition of the protein $\propto$ synuclein in brain tissue, including Parkinson's disease, multiple systems atrophy (MSA), pure autonomic failure (PAF) and Lewy body dementia. There are also a host of metabolic, autoimmune and neoplastic conditions that predispose to $\mathrm{NOH}$, most commonly diabetic autonomic neuropathy (Table 1). ${ }^{6}$ Neurogenic orthostatic hypotension is also associated with aging, with increased prevalence in frail elderly and particularly, hospitalized patients. ${ }^{6,10,11}$

Commonly prescribed medications increase the risk of orthostatic symptoms. Clinicians should be aware of the common classes of medications that cause or exacerbate $\mathrm{NOH}$, including alpha-blockers, anti-psychotics, antihypertensives and diuretics, antiparkinsonians, beta blockers, marijuana, phosphodiesterase inhibitors, tricyclic antidepressants and vasodilators. ${ }^{12}$ Identification of these medications and dosing adjustment/discontinuation where indicated is the first step in $\mathrm{NOH}$ management (see below). Common medications shown to carry the highest risk of $\mathrm{NOH}$ in elderly populations are hydrochlorthiazide, lisinopril, furosemide, trazodone and terazosin. ${ }^{13}$ The risk of $\mathrm{NOH}$ also increases with the absolute number of medications prescribed. ${ }^{13}$

\section{Clinical presentation}

Patients with NOH present with a wide constellation of both specific and generalized symptoms, making it difficult to recognize based on history alone. Cardinal features of NOH such as lightheadedness, dizziness, pre-syncope and syncope upon standing are common, but may not be present. ${ }^{14,15}$ Non-specific complaints including weakness, fatigue, cognitive changes, blurred vision, tinnitus, "coat hanger" neck pain (in the suboccipital and paracervical regions), pallor, anxiety, palpitations and nausea have also been reported with less frequency. ${ }^{14,15}$ Cognitive dysfunction is the prevailing symptom in patients over 70-years-old. ${ }^{15}$ The authors' experience is that non-specific fatigue/malaise may be the only presenting feature of $\mathrm{NOH}$. In cases where a diagnosis is elusive, bedside postural blood pressure (BP) and heart rate measurements are simple to

Table 1: Diseases associated with neurogenic orthostatic hypotension

\begin{tabular}{|c|c|}
\hline Category & Disease \\
\hline \multicolumn{2}{|c|}{ Neurodegenerative } \\
\hline & Pure autonomic failure (PAF)* \\
\hline & Parkinson's disease* \\
\hline & Multiple systems atrophy (MSA)* \\
\hline & Dementia with Lewy bodies* \\
\hline & Olivopontocerebellar atrophy \\
\hline & Baroreflex failure \\
\hline & Posterior fossa tumours \\
\hline & Wernicke-Korsakoff syndrome \\
\hline \multicolumn{2}{|c|}{ Spinal cord } \\
\hline & Traumatic tetraplegia \\
\hline & Syringiomyelia \\
\hline & Subacute combined degeneration \\
\hline & Spinal cord tumours \\
\hline \multicolumn{2}{|c|}{ Inflammatory/Autoimmune } \\
\hline & Multiple sclerosis \\
\hline & Guillain-Barré syndrome \\
\hline & Autoimmune autonomic ganglionopathy \\
\hline & Autoimmune autonomic neuropathy \\
\hline & $\begin{array}{l}\text { Sensory neuropathy with autonomic failure } \\
\text { (most commonly associated with Sjogren's) }\end{array}$ \\
\hline \multicolumn{2}{|l|}{ Neoplastic } \\
\hline & Posterior fossa tumours \\
\hline & Spinal cord tumours \\
\hline & $\begin{array}{l}\text { Paraneoplastic acute or chronic autonomic } \\
\text { neuropathy }\end{array}$ \\
\hline \multicolumn{2}{|c|}{$\begin{array}{l}\text { Chronic peripheral } \\
\text { autonomic neuropathies }\end{array}$} \\
\hline & Pure adrenergic neuropathy \\
\hline & Diabetic autonomic neuropathy \\
\hline & Amyloidosis \\
\hline & $\begin{array}{l}\text { Familial dysautonomia (Riley-Day } \\
\text { syndrome) }\end{array}$ \\
\hline & Dysautonomia of old age \\
\hline \multicolumn{2}{|c|}{ Toxic neuropathies } \\
\hline & Drug-induced acute autonomic neuropathy \\
\hline & Toxic acute autonomic neuropathy \\
\hline & Botulism \\
\hline & Porphyria \\
\hline
\end{tabular}

Table compiled with the aid of references ${ }^{6,10,11} * \propto$-synucleinopathy 
perform and may provide objective evidence for further investigation. Inquiries should be made regarding exacerbating factors that raise suspicion of an autonomic cause for these symptoms including prolonged standing, cardiovascular exercise, hot environments (e.g. after a bath), alcohol or any other factor that causes peripheral vasodilation. Valsalva maneuver with heavy lifting, straining or defecation can increase intrathoracic pressure and reduce venous return, leading to orthostatic symptoms. ${ }^{16}$ Temporality of symptoms should also be established, as $\mathrm{NOH}$ tends to be most severe in the morning upon awakening secondary to nocturnal diuresis. That is secondary to the high prevalence of supine hypertension that is known to occur in patients with $\mathrm{NOH} .{ }^{17}$ Large meals also induce redistribution of blood flow to the digestive system causing postprandial ( $\sim 30$ minutes) worsening of symptoms. ${ }^{18}$ Querying patients about standing time until onset of orthostatic symptoms may also raise suspicion for $\mathrm{NOH}$, as the majority of patients report asymptomatic standing times of $\sim 5$ minutes (min) or less. ${ }^{6}$

Patients may also present with several other features of dysautonomia or with characteristics of motor dysfunction or peripheral neuropathy. ${ }^{7}$ The history should include relevant questions about gastrointestinal, bladder, sexual and sudomotor dysfunction that increase the likelihood of a diagnosis of dysautonomia. It is important to remember that the extensive differential diagnosis for autonomic dysfunction necessitates a detailed neurological examination to look for features associated with particular disease processes. Parkinsonian features, cognitive dysfunction, ataxia and signs of peripheral neuropathy or end organ damage may also be elicited.

History and physical examination should also be directed at ruling out potentially reversible and dangerous causes of orthostatic intolerance. Cardiac and endocrine abnormalities as well as intravascular volume depletion can mimic $\mathrm{NOH}$. However, these usually present as acute orthostatic intolerance, whereas $\mathrm{NOH}$ secondary to autonomic dysfunction has a more insidious course. A detailed list of non-neurogenic causes of orthostatic hypotension is available elsewhere. ${ }^{12,19}$

\section{Assessment}

Measurement of orthostatic vitals at the bedside is a simple and easy screening method for $\mathrm{NOH}$. However their utility in ruling out a diagnosis is poor (Sensitivity $15.5 \%$, Specificity $89.9 \%$ and positive predictive value $61.7 \%) .{ }^{20}$ Therefore, clinicians must maintain a high degree of suspicion for $\mathrm{NOH}$ if symptoms are consistent with autonomic dysfunction, even in the absence of a significant orthostatic BP drop at the bedside. Prior to referral to the autonomic specialist for autonomic testing, a number of ancillary tests may be performed to rule out common mimics. These tests include screening for cardiac abnormalities (electrocardiogram, echocardiography, telemetry), measurement of intravascular volume status (serum complete blood count, electrolytes, blood urea nitrogen-to-creatinine ratio), screening for endocrine abnormalities (morning cortisol), peripheral neuropathy screen (vitamin $\mathrm{B}_{12}$, fasting plasma glucose) and brain imaging for structural abnormalities. ${ }^{12}$

Laboratory testing of autonomic function by the autonomic neurologist or cardiologist includes measures of sudomotor function, heart rate response to deep breathing, heart rate and BP responses to Valsalva maneuver, heart rate and $\mathrm{BP}$ responses to
HUT and thermoregulatory sweat testing. Cardiovascular response to HUT is the current gold standard for diagnosis of $\mathrm{NOH}$, as it measures the sympathetic response to orthostatic stress (Figure 2). Briefly, the patient is required to be resting supine in a quiet room for $15 \mathrm{~min}$ prior to HUT, while beat-tobeat BP and heart rate are recorded. The automated table is tilted slowly ( 10 seconds (s)) until an upright angle of 70 degrees is reached. Patients remain upright for five minutes, followed by a five minute supine measurement interval. A characteristic response to HUT in a patient with pure autonomic failure is shown in Figure 2 (SBP drop without concomitant heart rate increase). Three common responses are seen on HUT in patients with NOH: 1) a sustained, slow drop in BP (classical $\mathrm{NOH}$

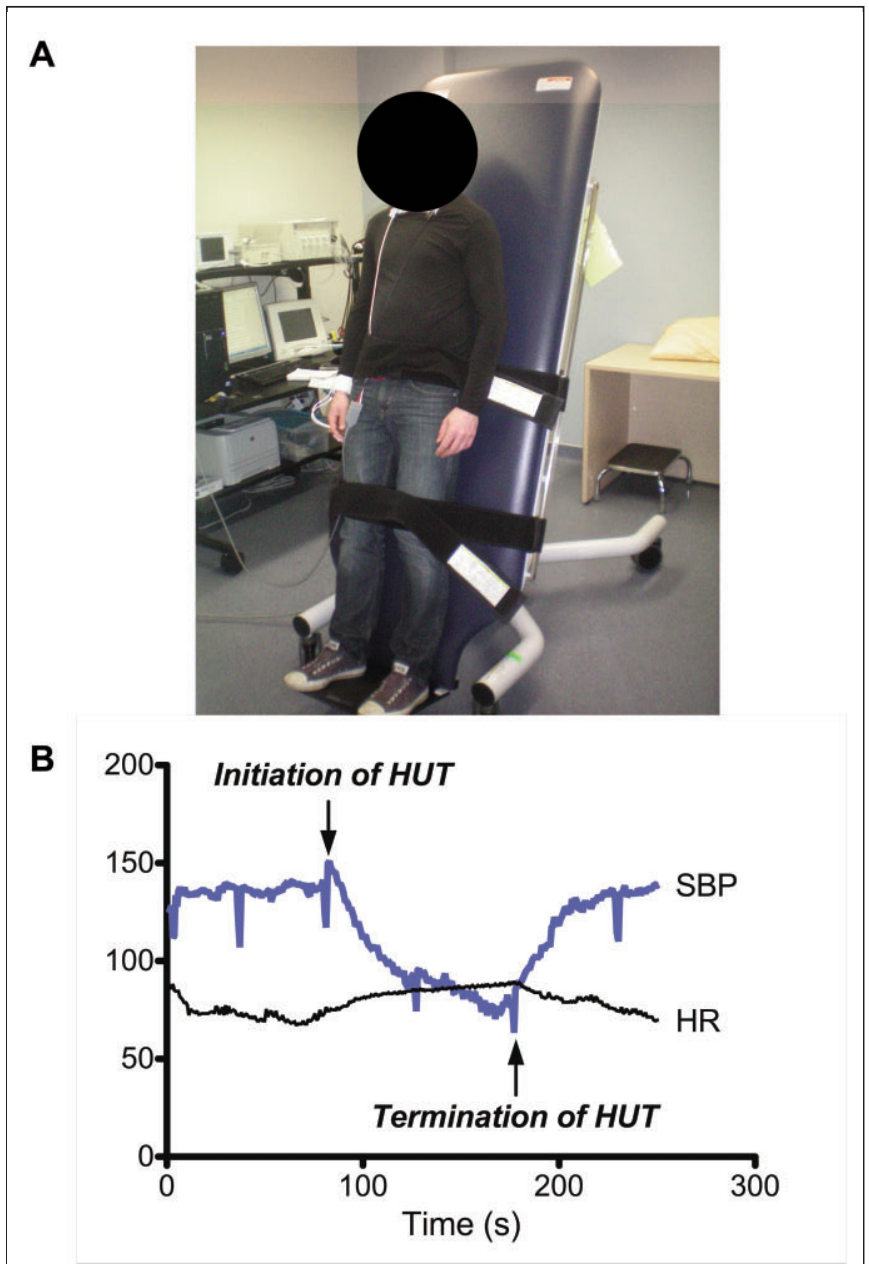

Figure 2: Panel A illustrates the standard laboratory protocol for headup tilt testing. Note heart rate leads and venous finger cuff sphygmomanometry for measurement of beat-to-beat blood pressure. The table is tilted to an upright position of 70 degrees. Panel $B$ displays a characteristic cardiovascular reaction to head-up tilt in a patient with pure autonomic failure. Note the slow and precipitous decline in systolic blood pressure without concomitant increase in heart rate to maintain cardiac output. HUT: head-up tilt; SBP: systolic blood pressure ( $\mathrm{mmHg}) ;$ HR: heart rate (beats/minute). 
Table 2: Non-pharmacologic treatment for neurogenic orthostatic hypotension

\begin{tabular}{l} 
Management Strategy \\
\hline Frequent documentation of postural BP, precipitating factors and \\
temporality of symptoms \\
Avoidance of large meals, carbohydrates and alcohol \\
Gradual, staged transitions from a supine position \\
Avoidance of Valsalva maneuvers \\
Elevating the head of the bed $10-20$ degrees \\
Physical counter maneuvers \\
Increased salt/fluid intake \\
Avoidance of excessive caffeine use \\
Abdominal binders and compression stockings \\
Aerobic and resistance exercise
\end{tabular}

$\mathrm{BP}$, blood pressure

variant), 2) an immediate and precipitous drop in BP within $\sim 15$ seconds of HUT (i.e. initial NOH variant), ${ }^{21} 3$ ) maintenance of BP for $\sim 3$ minutes followed by precipitous drop (i.e. delayed $\mathrm{NOH}$ variant). ${ }^{22}$ The three variants of $\mathrm{NOH}$ are each associated with their own symptomatology. In classical $\mathrm{NOH}$, patients are likely to experience dizziness, fatigue, sensorial disturbances and occasionally syncope, between $30 \mathrm{~s}$ and $3 \mathrm{~min}$ of HUT. Patients will experience similar symptoms in the initial $\mathrm{NOH}$ variant, however the onset will be immediately after HUT. In the delayed $\mathrm{NOH}$ variant, patients will experience prolonged prodromal symptoms including dizziness, fatigue, nausea, hyperhidrosis, sensorial disturbances, upper body muscle pain and frequently will experience syncopal events. ${ }^{23}$

\section{Management of neurogenic orthostatic hypotension}

A multifaceted approach to treatment of $\mathrm{NOH}$ should include identification of potential hypotensive medications, patient education, non-pharmacologic management (a list of patient education strategies and non-pharmacologic treatments are listed in Table 2 and an approach to pharmacotherapy is presented in Figure 3. Medications that can exacerbate orthostatic symptoms should be discontinued if possible. Alternatively, dosing regimens for necessary medications can be altered (e.g. changing anti-hypertensives to nighttime dosing). A systematic review of the literature on non-pharmacologic and pharmacologic management of $\mathrm{NOH}$ is available elsewhere. ${ }^{24}$

\section{Patient education and non-pharmacologic management}

Patient education is the initial component of the management strategy and significant time should be allotted for this at the time of diagnosis. Frequent documentation of BP as well as precipitating factors (e.g. large meals, alcohol, etc.) and the temporality of symptoms (e.g. post-prandial, early morning, etc.) in a diary will help patients identify risk factors so that behaviours can be modified. Advising the patient to avoid large meals comprising a high proportion of carbohydrates, as well as alcohol can attenuate post-prandial symptoms. Gradual and staged movement, such as moving from lying-to-sitting-tostanding over the course of 10-15 minutes, rather than moving immediately to standing can help reduce syncopal episodes upon awakening $^{17}$ and should be encouraged. Avoiding Valsalva maneuvers (which increase intrathoracic pressure) during heavy lifting, straining or defecation can be useful in preventing symptoms during vulnerable activities. ${ }^{17}$ Nocturnal pressure diuresis attributed to supine hypertension in patients with $\mathrm{NOH}$, can lead to volume depletion and subsequently symptom

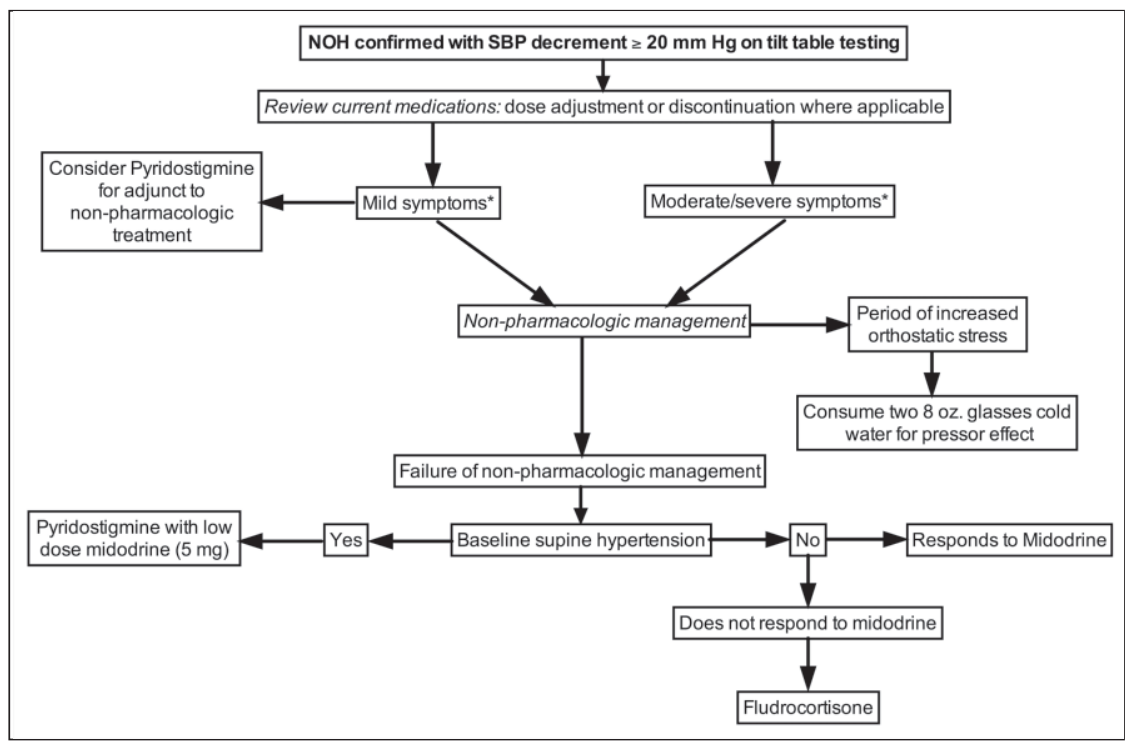

Figure 3: A practical approach to treatment of a patient with clinically defined neurogenic orthostatic hypotension including non-pharmacologic and pharmacologic measures. *Symptom severity classification into mild, moderate and severe can be done clinically according to the criteria outlined by Low et al. ${ }^{6}$ 
Table 3: Commonly used medications in the treatment of Neurogenic Orthostatic Hypotension (NOH)

\begin{tabular}{|c|c|c|c|c|}
\hline Medication & $\underline{\text { Dosages }}$ & $\underline{\text { Indications* }}$ & $\underline{\text { Common side effects }}$ & $\underline{\text { Other considerations }}$ \\
\hline Midodrine & $\begin{array}{l}2.5 \text { to } 5 \mathrm{mg} \text { once to twice daily } \\
\text { titrated to effect. Maximal dosages } \\
\text { primarily limited by supine } \\
\text { hypertension. }\end{array}$ & $\begin{array}{l}\text { Usually used with more severe } \\
\mathrm{NOH}\end{array}$ & $\begin{array}{l}\text { Supine hypertension; urinary } \\
\text { retention }\end{array}$ & $\begin{array}{l}\text { Pregnancy category } \mathrm{C} \text {; easier to } \\
\text { modify timing and titration of } \\
\text { dosages to fit patient needs }\end{array}$ \\
\hline Fludrocortisone & 0.05 to $0.2 \mathrm{mg}$ daily & $\mathrm{NOH}$ & $\begin{array}{l}\text { Supine hypertension; fluid } \\
\text { overload; hypokalemia }\end{array}$ & Pregnancy category $\mathrm{C}$ \\
\hline Pyridostigmine & $\begin{array}{l}60 \mathrm{mg} \text { twice to three times per day. } \\
\text { Long acting forms } 180 \mathrm{mg} \text { daily }\end{array}$ & $\begin{array}{l}\text { NOH; Milder orthostatic } \\
\text { symptoms; May be used in } \\
\text { combination with Midodrine }\end{array}$ & $\begin{array}{l}\text { Gastrointestinal upset, occasional } \\
\text { bradycardia }\end{array}$ & $\begin{array}{l}\text { May be used in combination with } \\
\text { Midodrine for initial therapy; } \\
\text { minimal effects on supine } \\
\text { hypertension; Pregnancy category C }\end{array}$ \\
\hline
\end{tabular}

*These indications are intended as general guidelines based on the authors' experience

exacerbation in the morning upon awakening. ${ }^{17}$ This phenomenon can be mitigated by raising the head of the bed 10 20 degrees, which has been shown to reduce venous return and shift fluid to the extra-cellular space. ${ }^{25}$

Following patient education, the effectiveness of nonpharmacologic management is well established. ${ }^{26}$ The modalities directly target the underlying pathophysiology of $\mathrm{NOH}$ by reducing venous pooling and increasing plasma volume. They are well-tolerated and relatively safe compared to pharmacotherapy, which poses the risk of causing or exacerbating supine hypertension (see below). Furthermore, non-pharmacologic management empowers patients to individually tailor their treatment regimens and gain a measure of control over their symptoms. There are a number of evidencebased non-pharmacologic modalities that should be prescribed to every patient with $\mathrm{NOH}$.

\section{Countermaneuvers}

Actions such as isometric tensing of the quadriceps, gluteal and abdominal muscles, leg-crossing, squatting, knee flexing, toe raises and trunk bending can increase standing time ${ }^{27}$ by increasing venous return and thus cardiac output and BP in order to maintain cerebral perfusion pressure while standing. ${ }^{28,29}$ These maneuvers can be used either during prolonged standing or to attenuate or arrest hypotensive symptoms at their onset. ${ }^{26}$

\section{Increased salt and fluid intake}

Maintenance of plasma volume is crucial in patients with inadequate vasoconstrictor mechanisms in order to avoid relative hypovolemia. ${ }^{6,30}$ Increased dietary salt leads to increased extracellular fluid volume, including intravascular volume. The recommended daily salt intake for patients with $\mathrm{NOH}$ is $10-20 \mathrm{~g}$ (180-360 mmol). ${ }^{6}$ Dietary increases can be achieved through liberal salt addition to meals or with $0.5 \mathrm{~g}$ and $1.0 \mathrm{~g}$ salt tablets in patients with intact renal function. However, it is our experience that the amount of salt in the North American diet continues to increase, making it easier to obtain target levels for sodium excretion (see below). Increased dietary salt loading should be accompanied by increased fluid intake of 2.0-2.5 L/day. Fluid in the form of sports drinks with electrolyte supplement has been anecdotally beneficial in our patients. The effect of salt and fluid loading can be monitored at home by the patient and during routine clinic visits. Producing "clear, colourless urine" provides the patient with a visual target for maintaining adequate plasma volume. ${ }^{26}$ A 24-hour urinary sodium excretion of $170 \mathrm{mmol}$ or greater is the laboratory benchmark for the salt loading regimen and at least a total 24hour urine output of $1.5 \mathrm{~L}$ is a reasonable surrogate to ensure appropriate plasma volume. ${ }^{31}$ Beneficial effects can be experienced as early as three days after initiation of salt loading. If symptoms are not improved after one week, or with exacerbations of symptoms, a 24-hour urine collection for total urine volume and sodium excretion is indicated to determine if attempts at improving blood volume are adequate. ${ }^{32}$

Close monitoring for signs of salt overload is also critical as patients with $\mathrm{NOH}$ are susceptible to developing supine hypertension. ${ }^{33}$ A $10 \mathrm{~g}$ daily dose of salt is double the amount recommended by the World Health Organization ${ }^{34}$ and is associated with hypertension leading to unintended cardiovascular outcomes in the patient with $\mathrm{NOH}$. Should salt loading be accompanied by new or worsening supine hypertension, alternative treatment modalities are indicated.

Increased fluid intake may also be used for expectant management of acute exacerbations of orthostatic intolerance. During periods of anticipated orthostatic stress (e.g. standing for prolonged periods, sitting in hot, humid weather), a useful strategy is to consume two $250 \mathrm{~mL}$ cups of cool water in rapid succession. This can increase SBP by up to $20 \mathrm{mmHg}$ for up to two hours. ${ }^{35,36}$ This may also have the benefit of enhancing the pressor effect of vasocontrictor medications. ${ }^{37}$

\section{Abdominal binders and compression stockings}

Tight-fitting abdominal binders, lower extremity compression stockings or compression shorts are useful to reduce venous pooling if they are put on prior to standing. ${ }^{6}$ These garments have been shown to maintain BP and increase 
stroke volume in elderly subjects and patients with autonomic failure during HUT. ${ }^{38,39}$ The abdomen is the most important site for these garments, as the majority of venous pooling occurs in the splanchnic venous system. ${ }^{40}$ These garments may be cosmetically displeasing or cumbersome to patients, particularly in hot weather, but they can be used intermittently during periods of heightened orthostatic stress (e.g. during exercise). In the majority of cases, an abdominal binder is well-tolerated and can be worn under light clothing.

\section{Exercise}

Although not well-studied in autonomic failure, a combination of resistance and aerobic exercises may specifically target $\mathrm{NOH}$ symptoms, as well as improve general health. Exercise is particularly effective in combating $\mathrm{NOH}$ symptoms that accompany deconditioning states such as bed rest. Aerobic exercise has been shown to expand plasma volume, and resistance training of the abdominal and lower extremity musculature can improve the effectiveness of the skeletal muscle pump to reduce venous pooling. ${ }^{26,41,42} \mathrm{~A}$ practical approach to initiating an exercise program must be provided to ensure compliance. It must also be considered that exercise can adversely exacerbate postural hypotension in patients with autonomic failure, as the sympathetic response to exercise is blunted..$^{43}$ Other non-pharmacologic strategies, such as adequate hydration, avoiding food intake prior to exercise onset, countermaneuvers and compression garments previously mentioned, can attenuate exercise-induced hypotension. Furthermore, exercising in a supine or sitting position (e.g. recumbent cycle ergometer) should be advised. Further study is required to determine optimal exercise prescription and dose.

\section{Pharmacotherapy}

When non-pharmacologic management fails or orthostatic BP control remains suboptimal, pharmacologic agents may be used. It must be emphasized that pharmacotherapy is usually ineffective, especially with progressive $\mathrm{NOH}$, if nonpharmacologic management is not used in combination. The central principle of pharmacologic management of $\mathrm{NOH}$ is to achieve an appropriate increase in standing BP through either a pressor effect or an increase in plasma volume, without causing or minimizing supine hypertension $(\geq 180 / 110 \mathrm{mmHg}$ ). Clinicians should be aware of the high prevalence of supine hypertension that exists as part of the natural history of many dysautonomias $^{33}$ and practice slow medication titration with frequent monitoring so that a balance can be achieved between supine and standing BP. The highest level of evidence exists for the sympathomimmetic Midodrine (Amatine ${ }^{\circledR}$, Apomidodrine $\left({ }^{\circledR}\right)$, which has been subject to a double-blind, placebocontrolled trial. ${ }^{44}$ Other commonly used medications include Pyridostigmine (Mestinon ${ }^{\circledR}, \quad$ Mestinon $\quad$ SR $\AA$ ) and Fludrocortisone (Florinef $\AA$ ). A summary of the practical recommendations on the use of common medications for $\mathrm{NOH}$ are presented in Table 3. Adjuncts used for refractory NOH or to target particular symptoms (e.g. Octreotide for post-prandial $\mathrm{NOH}$ ) are also briefly discussed. A simple treatment algorithm including non-pharmacologic and pharmacologic treatment is presented in Figure 3.

\section{Midodrine}

Midodrine is the best studied of the NOH medications. ${ }^{44,45} \mathrm{~A}$ peripherally selective alpha-1-adrenoreceptor agonist, it acts as a vasopressor to increase venomotor and vasomotor tone, resulting in elevated standing SBP. Optimal symptom control usually occurs at a dose of $10 \mathrm{mg}$ orally, three times daily. ${ }^{44}$ The initial dose is $2.5 \mathrm{mg}$, one to three times per day with dose increasing by $2.5 \mathrm{mg}$ weekly until maximum daily dosing or optimal symptom control has been achieved. Midodrine requires slow titration and frequent $\mathrm{BP}$ monitoring due to the high risk of supine hypertension. ${ }^{16}$ Accordingly, it is well established that Midodrine should not be taken in the evening (usually not after $6 \mathrm{pm}) .^{5}$ Care should be taken in patients with baseline supine hypertension and other $\mathrm{NOH}$ drugs should be considered. Dosing regimens should also take into account that the duration of action is two to four hours with an onset of $0.5-1$ hour. ${ }^{5,16}$ Therefore, it can be taken prior to mealtime to mitigate postprandial exacerbation of NOH. Adverse effects other than supine hypertension include urinary retention, piloerection, pruritis, and gastrointestinal upset.

\section{Pyridostigmine}

Pyridostigmine has emerged as both an alternative and adjunct to midodrine. ${ }^{5}$ Pyridostigmine is an acetylcholinesterase inhibitor used predominantly in the treatment of myasthenia gravis. Pyridostigmine presumably exerts its effect during standing when baroreceptors are unloaded and sympathetic ganglionic transmission, mediated through acetylcholine, is increased. By inhibiting the breakdown of acetylcholine in the synaptic cleft, Pyridostigmine causes a mild increase in DBP during standing, while at the same time avoiding unwanted supine hypertension. ${ }^{46,47}$ Pyridostigmine is indicated as frontline treatment on its own in those with mild orthostatic symptoms due to the modest increase in standing BP. ${ }^{6}$ It is started at $30 \mathrm{mg}$ two or three times daily and increased to $60 \mathrm{mg}$ three times daily. The combination of Pyridostigmine with 2.5-5 mg once to twice daily doses of Midodrine has also been shown to improve orthostatic symptoms without causing supine hypertension. ${ }^{47}$ Common side effects of Pyridostigmine are cholinergic, including diaphoresis, hypersalivation, diarrhea and muscle cramping. ${ }^{48}$

\section{Fludrocortisone}

Fludrocortisone is a synthetic mineralocorticoid, which acts as an aldosterone receptor agonist to increase plasma volume and improve blood vessel sensitivity to circulating catecholmines ${ }^{30,49,50}$ It is indicated in patients with moderate-tosevere symptoms who do not respond to Midodrine or in patients who do not tolerate dietary increases in salt and fluid. ${ }^{6}$ Treatment is initiated at a dose of $0.1 \mathrm{mg}$ and can be increased to up to 0.3 mg per day in refractory patients. Side effects tend to occur much more frequently at higher doses. Drug monitoring should include both BP monitoring and weight measurement, as patients should expect to gain $\sim 2-3 \mathrm{~kg}$ before symptoms resolve. Regular electrolyte monitoring is also indicated due to the high risk of hypokalemia, and it is recommended that patients consume potassium-containing fruits and vegetables (e.g. bananas).$^{30}$ As with Midodrine, supine hypertension with higher doses is also a 
concern. ${ }^{50}$ Other side effects include peripheral edema, headache and occasionally congestive heart failure.

\section{Adjuncts}

The role of adjunct medications in treatment of $\mathrm{NOH}$ is to target specific pathophysiological processes in a subset of patients. These medications do not have the same body of evidence as those listed above and are not as well tolerated as frontline medications. They are usually considered only by an autonomic specialist.

Vasopressin analogues are considered to reduce nocturnal diuresis and subsequently prevent orthostatic symptoms upon awakening. They are usually reserved for patients with MSA, who have impaired hypothalamic release of vasopressin, or patients with nocturnal supine hypertension who are at higher risk for significant nocturnal intravascular volume loss. ${ }^{16,51}$ It is administered intranasally at a dose of 5-40 $\mu \mathrm{g}$ at bedtime. Side effects include water intoxication and hyponatremia, although these can usually be avoided at lower doses. ${ }^{52}$

Post-prandial hypotension is particularly problematic for patients with gastroparesis secondary to diabetic autonomic neuropathy. ${ }^{53}$ When non-pharmacologic management fails (see above), there is some evidence that Octreotide can be given subcutaneously (25-200 $\mu \mathrm{g})$ with a meal to increase the rate of gastric emptying. ${ }^{54}$ Because it is administered parenterally, it is usually reserved for refractory cases of post-prandial hypotension.

Erythropoietin has the dual effect of increasing standing BP and treating the normocytic, normochromic anemia that accompanies autonomic failure and diabetic autonomic neuropathy. ${ }^{55,56}$ It is administered three times per week, either subcutaneously or intravenously in $25-75 \mathrm{U} / \mathrm{kg}$ doses. Again, care must be taken to monitor for supine hypertension. ${ }^{55,56}$

\section{Conclusion}

This review provides a practical approach to the diagnosis, assessment and management of $\mathrm{NOH}$. Clinicians should be aware of the broad differential diagnosis, variable presentation and complex management of this common condition. The effectiveness and safety of non-pharmacologic management has been highlighted, along with potentially useful medications and their relative contraindications and side effects.

\section{REFERENCES}

1. Rose KM, Eigenbrodt ML, Biga RL, et al. Orthostatic hypotension predicts mortality in middle-aged adults: the Atherosclerosis Risk In Communities (ARIC) Study. Circulation. 2006;114(7): 630-6.

2. Cordeiro RC, Jardim JR, Perracini MR, Ramos LR. Factors associated with functional balance and mobility among elderly diabetic outpatients. Arq Bras Endocrinol Metabol. 2009;53(7): 834-43.

3. Bendini C, Angelini A, Salsi F, et al. Relation of neurocardiovascular instability to cognitive, emotional and functional domains. Arch Gerontol Geriatr. 2007;44 Suppl 1:69-74.

4. Freeman R, Wieling W, Axelrod FB, et al. Consensus statement on the definition of orthostatic hypotension, neurally mediated syncope and the postural tachycardia syndrome. Clin Auton Res. 2011;21(2):69-72.

5. Low PA, Singer W. Management of neurogenic orthostatic hypotension: an update. Lancet Neurol. 2008;7(5):451-8.
6. Low PA, Fealy RD. Managment of neurogenic orthostatic hypotension. In: Low PA, Benarroch EE, editors. Clinical autonomic disorders. 3rd ed. Philadelphia: Wolters Kluwer Health/Lippincott Williams \& Wilkins; 2008. p. 547-59.

7. Freeman R. Clinical practice: neurogenic orthostatic hypotension. N Eng J Med. 2008;358:615-24.

8. Metzler M, Duerr S, Granata R, Krismer F, Robertson D, Wenning GK. Neurogenic orthostatic hypotension: pathophysiology, evaluation, and management. J Neurol. 2013;260(9):2212-19.

9. Smit AA, Halliwill JR, Low PA, Wieling W. Pathophysiological basis of orthostatic hypotension in autonomic failure. J Physiol. 1999;519 Pt 1:1-10.

10. Masaki KH, Schatz IJ, Burchfiel CM, et al. Orthostatic hypotension predicts mortality in elderly men: the Honolulu Heart Program. Circulation. 1998;98(21):2290-5.

11. Ooi WL, Barrett S, Hossain M, Kelley-Gagnon M, Lipsitz LA. Patterns of orthostatic blood pressure change and their clinical correlates in a frail, elderly population. JAMA. 1997;277(16): 1299-304.

12. Lanier JB, Mote MB, Clay EC. Evaluation and management of orthostatic hypotension. Am Fam Physician. 2011;84(5):527-36.

13. Poon IO, Braun U. High prevalence of orthostatic hypotension and its correlation with potentially causative medications among elderly veterans. J Clin Pharm Ther. 2005;30(2):173-8.

14. Mathias CJ, Mallipeddi R, Bleasdale-Barr K. Symptoms associated with orthostatic hypotension in pure autonomic failure and multiple system atrophy. J Neurol. 1999;246(10):893-8.

15. Low PA, Opfer-Gehrking TL, McPhee BR, et al. Prospective evaluation of clinical characteristics of orthostatic hypotension. Mayo Clin Proc. 1995;70(7):617-22.

16. Freeman R. Current pharmacologic treatment for orthostatic hypotension. Clin Auton Res. 2008;18 Suppl 1:14-18.

17. Freeman R. Treatment of orthostatic hypotension. Semin Neurol. 2003;23(4):435-42.

18. Fujimura J, Camilleri M, Low PA, Novak V, Novak P, OpferGehrking TL. Effect of perturbations and a meal on superior mesenteric artery flow in patients with orthostatic hypotension. J Auton Nerv Syst. 1997;67(1-2):15-23.

19. Gupta V, Lipsitz LA. Orthostatic hypotension in the elderly: diagnosis and treatment. Am J Med. 2007;120(10):841-7.

20. Cooke J, Carew S, O'Connor M, Costelloe A, Sheehy T, Lyons D. Sitting and standing blood pressure measurements are not accurate for the diagnosis of orthostatic hypotension. QJM. 2009;102(5):335-9.

21. Wieling W, Krediet CT, van Dijk N, Linzer M, Tschakovsky ME. Initial orthostatic hypotension: review of a forgotten condition. Clin Sci (Lond). 2007;112(3):157-65.

22. Gibbons $\mathrm{CH}$, Freeman R. Delayed orthostatic hypotension: a frequent cause of orthostatic intolerance. Neurology. 2006;67(1): 28-32.

23. Fedorowski A, Melander O. Syndromes of orthostatic intolerance: a hidden danger. J Intern Med. 2012;273(4):322-35.

24. Logan IC, Witham MD. Efficacy of treatments for orthostatic hypotension: a systematic review. Age Ageing. 2012;41(5): 587-94.

25. Omboni S, Smit AA, van Lieshout JJ, Settels JJ, Langewouters GJ, Wieling W. Mechanisms underlying the impairment in orthostatic tolerance after nocturnal recumbency in patients with autonomic failure. Clin Sci (Lond). 2001;101(6):609-18.

26. Wieling W, Colman N, Krediet CT, Freeman R. Nonpharmacological treatment of reflex syncope. Clin Auton Res. 2004;14 Suppl 1:62-70.

27. Bouvette CM, McPhee BR, Opfer-Gehrking TL, Low PA. Role of physical countermaneuvers in the management of orthostatic hypotension: efficacy and biofeedback augmentation. Mayo Clin Proc. 1996;71(9):847-53.

28. Ten Harkel AD, van Lieshout JJ, Wieling W. Effects of leg muscle pumping and tensing on orthostatic arterial pressure: a study in normal subjects and patients with autonomic failure. Clin Sci (Lond). 1994;87(5):553-8.

29. Wieling W, van Lieshout JJ, van Leeuwen AM. Physical manoeuvres that reduce postural hypotension in autonomic failure. Clin Auton Res. 1993;3(1):57-65. 
30. Wieling W, Van Lieshout JJ, Hainsworth R. Extracellular fluid volume expansion in patients with posturally related syncope. Clin Auton Res. 2002;12(4):242-9.

31. El-Sayed H, Hainsworth R. Salt supplement increases plasma volume and orthostatic tolerance in patients with unexplained syncope. Heart. 1996;75(2):134-40.

32. Mtinangi BL, Hainsworth R. Early effects of oral salt on plasma volume, orthostatic tolerance, and baroreceptor sensitivity in patients with syncope. Clin Auton Res. 1998;8(4):231-5.

33. Naschitz JE, Slobodin G, Elias N, Rosner I. The patient with supine hypertension and orthostatic hypotension: a clinical dilemma. Postgrad Med J. 2006;82(966):246-53.

34. World Health Organization. Global status report on noncommunicable diseases. 2010:16-21.

35. Jordan J. Acute effect of water on blood pressure. What do we know? Clin Auton Res. 2002;12(4):250-5.

36. Jordan J, Shannon JR, Grogan E, Biaggioni I, Robertson D. A potent pressor response elicited by drinking water. Lancet. 1999; 353(9154):723.

37. Jordan J, Shannon JR, Diedrich A, Black B, Robertson D, Biaggioni I. Water potentiates the pressor effect of ephedra alkaloids. Circulation. 2004;109(15):1823-5.

38. Henry R, Rowe J, O'Mahony D. Haemodynamic analysis of efficacy of compression hosiery in elderly fallers with orthostatic hypotension. Lancet. 1999;354(9172):45-6.

39. Smit AA, Wieling W, Fujimura J, et al. Use of lower abdominal compression to combat orthostatic hypotension in patients with autonomic dysfunction. Clin Auton Res. 2004;14(3):167-75.

40. Denq JC, Opfer-Gehrking TL, Giuliani M, Felten J, Convertino VA, Low PA. Efficacy of compression of different capacitance beds in the amelioration of orthostatic hypotension. Clin Auton Res. 1997;7(6):321-6.

41. Mtinangi BL, Hainsworth R. Effects of moderate exercise training on plasma volume, baroreceptor sensitivity and orthostatic tolerance in healthy subjects. Exp Physiol. 1999;84(1):121-30.

42. Mtinangi BL, Hainsworth. R. Increased orthostatic tolerance following moderate exercise training in patients with unexplained syncope. Heart. 1998;80(6):596-60.

43. Low DA, da Nobrega AC, Mathias CJ. Exercise-induced hypotension in autonomic disorders. Auton Neurosci. 2012;171 (1-2):66-78.

44. Wright RA, Kaufmann HC, Perera R, et al. A double-blind, doseresponse study of midodrine in neurogenic orthostatic hypotension. Neurology. 1998;51(1):120-4.
45. Low PA GJ, Freeman R, Sheng KN, McElligott MA. Efficacy of midodrine vs placebo in neurogenic orthostatic hypotension. A randomized, double-blind multicenter study. Midodrine Study Group. JAMA. 1997;278(5):388.

46. Singer W, Opfer-Gehrking TL, Nickander KK, Hines SM, Low PA. Acetylcholinesterase inhibition in patients with orthostatic intolerance. J Clin Neurophysiol. 2006;23(5):476-81.

47. Singer W, Sandroni P, Opfer-Gehrking TL, et al. Pyridostigmine treatment trial in neurogenic orthostatic hypotension. Arch Neurol. 2006;63(4):513-18.

48. Gales BJ, Gales MA. Pyridostigmine in the treatment of orthostatic intolerance. Ann Pharmacother. 2007;41(2):314-18.

49. van Lieshout JJ, ten Harkel AD, Wieling W. Fludrocortisone and sleeping in the head-up position limit the postural decrease in cardiac output in autonomic failure. Clin Auton Res. 2000;10(1): $35-42$.

50. Chobanian AV, Volicer L, Tifft CP, Gavras H, Liang CS, Faxon D. Mineralocorticoid-induced hypertension in patients with orthostatic hypotension. N Engl J Med. 1979;301(2):68-73.

51. Kaufmann H, Oribe E, Miller M, Knott P, Wiltshire-Clement M, Yahr MD. Hypotension-induced vasopressin release distinguishes between pure autonomic failure and multiple system atrophy with autonomic failure. Neurology. 1992;42(3 Pt 1):590-3.

52. Sakakibara R, Matsuda S, Uchiyama T, Yoshiyama M, Yamanishi $\mathrm{T}$, Hattori T. The effect of intranasal desmopressin on nocturnal waking in urination in multiple system atrophy patients with nocturnal polyuria. Clin Auton Res. 2003;13(2):106-8.

53. Sasaki E, Kitaoka H, Ohsawa N. Postprandial hypotension in patients with non-insulin-dependent diabetes mellitus. Diabetes Res Clin Pract. 1992;18(2):113-21.

54. Armstrong E, Mathias CJ. The effects of the somatostatin analogue, octreotide, on postural hypotension, before and after food ingestion, in primary autonomic failure. Clin Auton Res. 1991;1 (2): $135-40$

55. Hoeldtke RD, Streeten DH. Treatment of orthostatic hypotension with erythropoietin. N Engl J Med. 1993;329(9):611-15.

56. Perera R, Isola L, Kaufmann $H$. Effect of recombinant erythropoietin on anemia and orthostatic hypotension in primary autonomic failure. Clin Auton Res. 1995;5(4):211-13. 